\title{
Stabilizing Effect of Biobased Additives on the Thermal Degradation of PVC
}

\author{
T.O. Egbuchunam ${ }^{1, a}$, F.E. Okieimen ${ }^{2, b}$ and D. Balköse ${ }^{3, c}$ \\ ${ }^{1}$ Department of Chemistry, Federal University of Petroleum Resources, PMB 1221, Effurun, \\ Delta State, Nigeria \\ ${ }^{2}$ University of Benin, Centre for Biomaterials Research, Benin City, Nigeria \\ ${ }^{3}$ Department of Chemical Engineering, Izmir Institute of Technology, Urla-Izmir, Turkey \\ ( ${ }^{\text {atessychunam@yahoo.com) }}, \underline{{ }^{b} \text { fexokieimen@yahoo.com, }}{ }^{\text {c devrimbalkose@iyte.edu.tr }}$
}

[Received 14 August 2009, accepted 18 January 2010]

Keywords: Biobased additives, PVC, Thermal stabilization

\begin{abstract}
Novel biobased additives prepared from rubber seed oil were evaluated as thermal stabilizer for PVC. Divalent metal (barium and cadmium) soaps of rubber seed oil were prepared by metathesis in aqueous alcohol and characterized by thermal methods (differential scanning calorimetry and thermogravimetry). The stabilizing effect of the soaps and their admixtures on the thermal degradation of PVC powder and plasticized PVC was examined by dynamic thermogravimetry and dehydrochlorination studies at $160^{\circ} \mathrm{C}$ using the Thermomat equipment. The metal soaps showed multiple decomposition endotherms but were generally stable (with weight loss less than $5 \%$ ) within the temperature range $\left(180-220^{\circ} \mathrm{C}\right)$ frequently used in the processing of PVC. Using the Broido model, values of apparent activation energy of decomposition of between 50 and $200 \mathrm{kJmol}^{-1}$ were obtained for the soaps. The biobased additives were found to be relatively effective in stabilizing PVC in powder and plasticized forms against thermal degradation. Using inhibition/retardation time, temperature of incipient decomposition, and temperature at which various extents of decomposition was attained as indices of thermal stabilization, the results from this study indicate a potential for the application of the biobased additives as thermal stabilizer for PVC in rigid and flexible formulations.
\end{abstract}

\section{Introduction}

Poly (vinyl chloride) (PVC) is a commonly used material employed for a wide range of applications, mainly due to its relative low cost and high versatility. Plasticized PVC (P-PVC) is a soft material widely used in industry for flexible applications. This is based on the combination of a PVC resin and a plasticizer agent to form a PVC paste or liquid plastisol which can be converted into a solid plastisol by controlled heating through a curing process [1]. On account of the low thermal stability of PVC at the molecular level, it has become the practice to process the polymer in the presence of heat stabilizing additives. For example, thermal stabilizers based on compounds with chemicals (lead, tin, barium, calcium or zinc), have been employed for decades to improve its stability during processing. The thermal degradation and stabilization of PVC has been studied extensively [2-10] because of its important practical/technological and scientific implication on the production and use of the polymer. Most of these investigations have been based on measurement of rates of evolution of gaseous products, thermogravimetry and analytical characterization of the residue of degradation. However, technical evaluation of candidate additive as thermal stabilizer for PVC is comparative rather than absolute measurement. It should therefore be possible to develop and/or adopt simple and reliable tools/equipment and/or indices for polymer 
and/or polymer additive evaluation. In this study, biobased additives produced from locally available renewable resource are evaluated as thermal stabilizers for PVC in rigid and plasticized forms.

\section{Experimental}

The PVC powder was supplied by Petkim, Turkey, (Petvinil P.38/74), and dioctylphthalate (DOP) from Merck. All the reagents were used as received. Rubber Seed Oil was obtained from Rubber Research Institute of Nigeria (RRIN), Iyanomon, Benin-City. The metal soaps (Ba and Cd) of rubber seed oil used in this study were prepared by metathesis in aqueous alcohol as described previously [11].

Sample preparation. Plasticized PVC was prepared by mixing with $80 \mathrm{phr}$ of dioctylphthalate (DOP) with PVC resin. Thermal studies were carried out using the pure polymer stabilized with 3 wt $\%$ of Ba and Cd soaps of RSO and their admixtures and plasticized PVC stabilized with 3 wt $\%$ of $\mathrm{Ba}$ and $\mathrm{Cd}$ soaps of RSO and their admixtures.

Characterization of metal soaps of RSO. The metal soaps ( $\mathrm{Ba}$ and $\mathrm{Cd}$ ) of RSO prepared by metathesis in alcohol solution were characterized by Differential Scanning Calorimetry (DSC) measurements using a Shimadzu DSC-50 analyser heated up to $200^{\circ} \mathrm{C}$ at a heating rate of $10^{\circ} \mathrm{C} / \mathrm{min}$ under $40 \mathrm{~cm}^{3} \mathrm{~min}^{-1}$ nitrogen gas flow and dynamic thermal gravimetric (TG) measurements using Shimadzu TGA-51. The samples were heated from 25 to $600^{\circ} \mathrm{C}$ at a heating rate of $10^{\circ} \mathrm{C} / \mathrm{min}$ under nitrogen atmosphere.

Dehydrochlorination studies on samples. Dehydrochlorination was monitored by conductivity measurement using the Thermomat 763 equipment. Detail description of the Thermomat equipment and its application in dehydrochlorination studies were given previously [5].

Thermogravimetric Analysis (TGA). Thermograms of the plastigels were obtained under nitrogen using the Shimadzu TGA-51 at a heating rate of $10^{\circ} \mathrm{C} / \mathrm{min}$ up to $600^{\circ} \mathrm{C}$. 


\section{Results and Discussion}

Thermal characterization of Ba and Cd soaps of RSO. The thermal degradation behaviours of barium and cadmium soaps of RSO were studied with TGA at a heating rate of $10^{\circ} \mathrm{C} / \mathrm{min}$ in nitrogen atmosphere. The thermograms obtained for barium and cadmium soaps of RSO are shown in Fig. I.

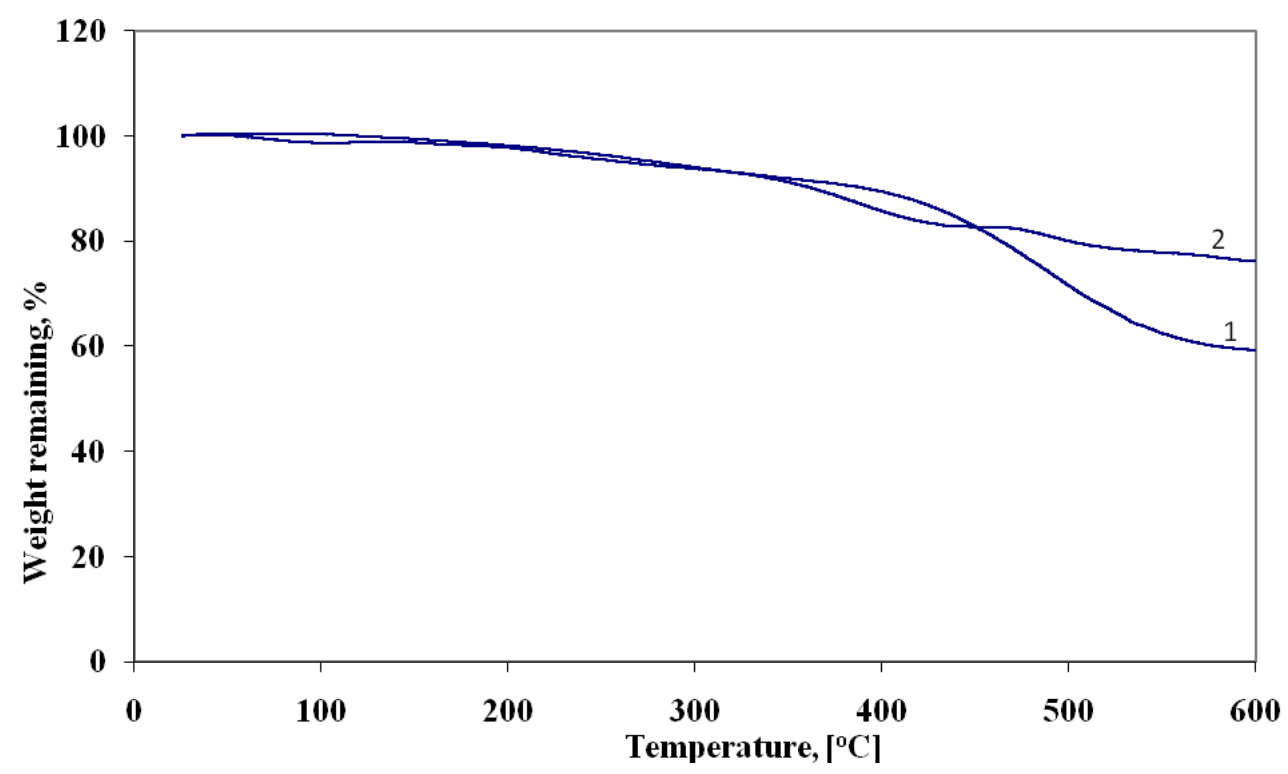

Fig. 1. TGA thermogram for (1) barium soap (2) cadmium soap of RSO

The metal soaps presented similar degradation behaviours. It is observed that the degradation pattern is a one-stage process. A relatively low stage with $3 \%$ weight loss below $200^{\circ} \mathrm{C}$, another $10 \%$ weight loss at temperatures between 200 and $300^{\circ} \mathrm{C}$, followed by an abrupt weight loss after $320^{\circ} \mathrm{C}$ for cadmium soap and after $400^{\circ} \mathrm{C}$ for barium soap. The decomposition of a metal soap usually depends upon the metal and the carboxylate chain having the oxides and carbonates of the metal present as the major decomposition products in the residue while carbon (IV) oxide, alkanes and ketones as gaseous products.

The activation energy of decomposition (Ea) of the metal soaps was calculated from TGA curves using the Broido equation [12]

$\operatorname{In}\{\operatorname{In}(1 / \alpha)\}=-\frac{E}{R T}+\operatorname{In} \frac{\left(R Z T_{m}^{2}\right)}{\beta E}$

The values of apparent activation energy of decomposition obtained from plots of $\operatorname{In}(\operatorname{In} 1 / \alpha)$ vs. $1 / \mathrm{T}$ (Fig. 2) by best-line fit method are $219.9 \mathrm{~kJ} / \mathrm{mol}$ and $66.30 \mathrm{~kJ} / \mathrm{mol}$ for barium and cadmium soaps of RSO respectively. 


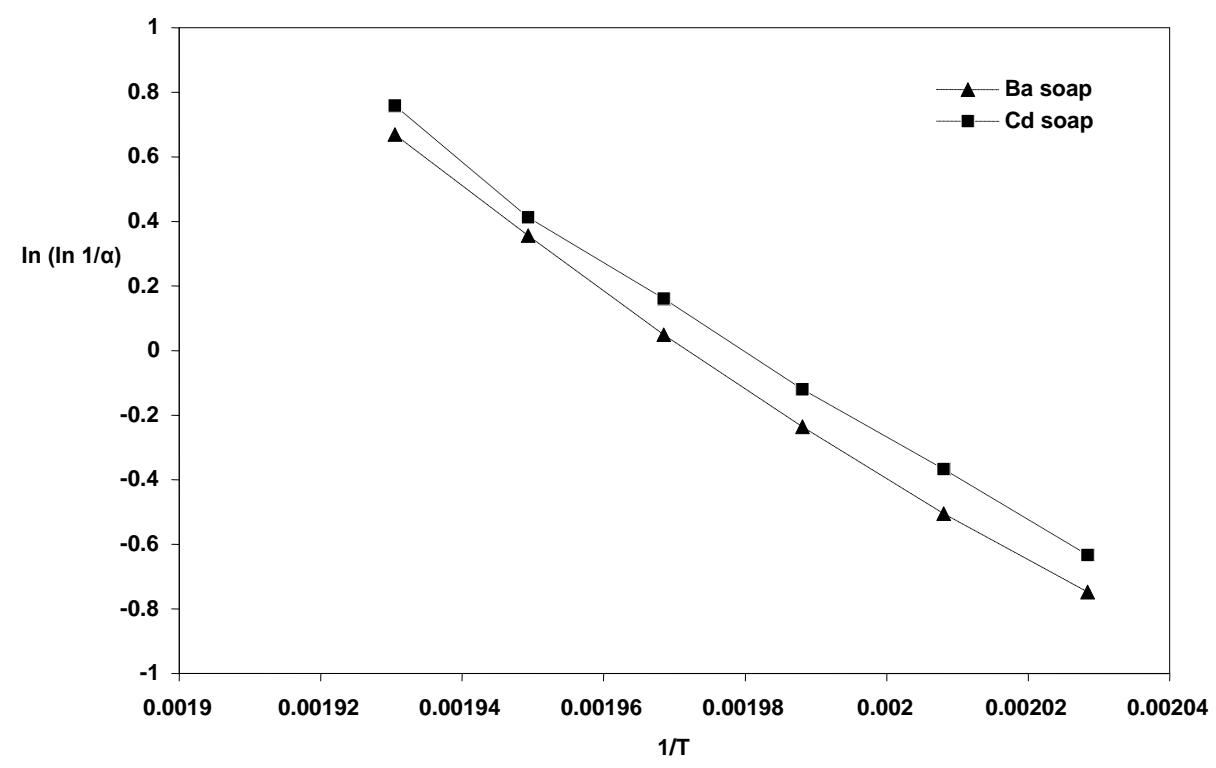

Fig. 2. Broido's plot for the thermal decomposition of metal soaps of RSO

Fig. 3 shows the DSC thermograms for $\mathrm{Ba}$ and Cd soaps of RSO. These measurements determine the transitions occurring during the thermal treatment of the metal soaps.

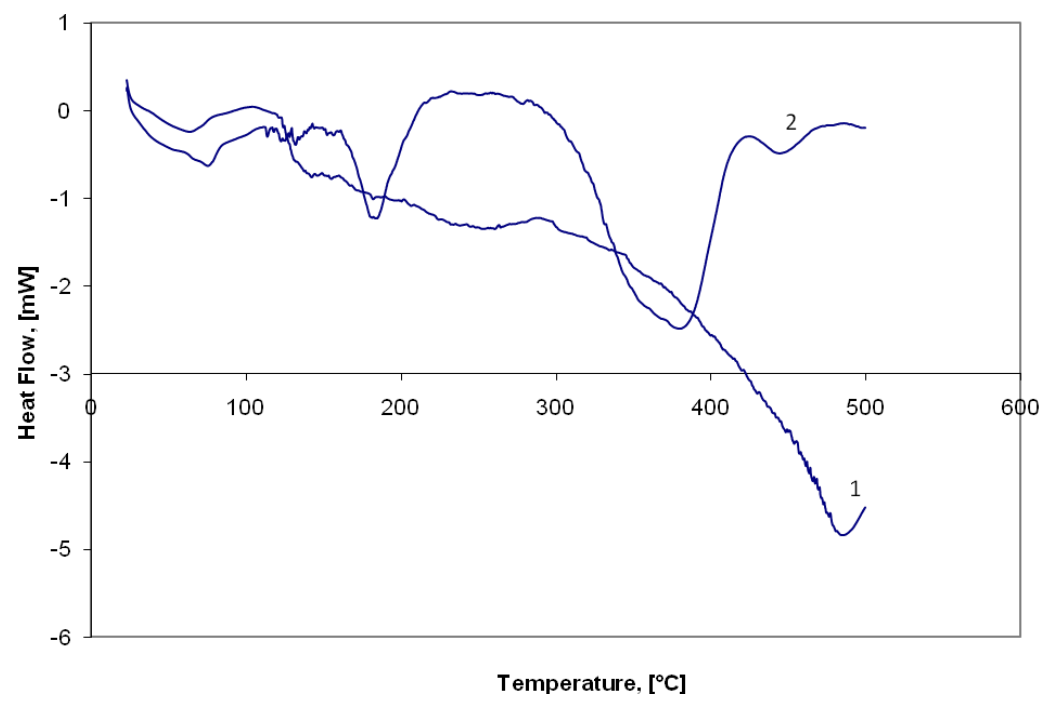

Fig. 3. DSC thermogram for (1) barium soap (2) cadmium soap of RSO

The curves show a single endothermic peak of a solid-liquid phase transition corresponding to melting below $100^{\circ} \mathrm{C}$. Other phase transitions observed from $100^{\circ} \mathrm{C}$ up to $200^{\circ} \mathrm{C}$ were attributed to the thermal decomposition of the soap. 


\section{Stabilization of PVC powder with Ba and Cd soaps of RSO.}

Thermal dehydrochlorination studies. The effectiveness of a stabilizer for PVC is usually measured by its ability to prevent dehydrochlorination at early stages of degradation. Dehydrochlorination rate measurements, particularly at the early stages of degradation provide reliable data on degradation and stabilization processes of PVC. The thermal degradation of PVC stabilized with $\mathrm{Ba}$ and $\mathrm{Cd}$ soaps of RSO and their admixtures was studied using the curves obtained from the conductivity measurements by the PVC Thermomat which detects the evolution of $\mathrm{HCl}$ at temperatures as low as $100^{\circ} \mathrm{C}$.

The dehydrochlorination curves obtained for unstabilized and stabilized PVC at $160^{\circ} \mathrm{C}$ are shown in Fig. 4.

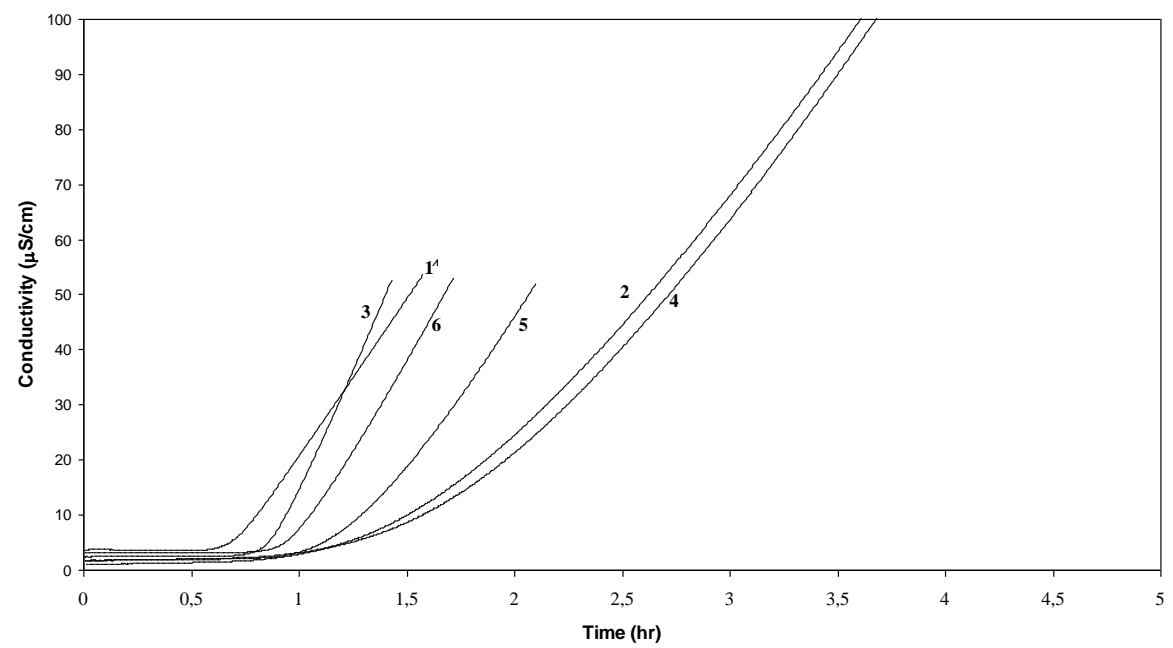

Fig. 4. Dehydrochlorination curves at $160^{\circ} \mathrm{C}$ for $\mathrm{PVC}$ polymer stabilized with 1) No soap 2) Ba soap 3) Cd soap 4) $10 \%$ Cd soap 5) $50 \%$ Cd soap 6) $90 \%$ Cd soap

It can be seen that the dehydrochlorination curves can be divided into two sections: an initial low rate of $\mathrm{HCl}$ evolution followed by a more rapid dehydrochlorination after consumption of the stabilizers. The dehydrochlorination process was characterized in terms of induction time (period of time before incipient change in conductivity) [5], which also mean inhibition/retardation time. The dehydrochlorination characteristics in terms of inhibition/retardation time and the relative retardation index are given in Table 1.

Table 1: Dehydrochlorination Characteristics obtained for stabilized PVC polymer

\begin{tabular}{lcc}
\hline Additive & Induction time $(\mathbf{h})$ & Retardation $\mathbf{i n d e x}\left(\mathbf{R}_{\mathbf{t}} / \mathbf{R}_{\mathbf{t}}^{\mathbf{0}}\right)$ \\
\hline None & 0.69 & 0.00 \\
Ba-RSO & 1.47 & 2.13 \\
Cd-RSO & 0.85 & 1.23 \\
Mixtures of Ba/Cd soaps of RSO & \\
$(\%$ Cd-soap content) & & \\
10 & 1.66 & 2.41 \\
50 & 1.10 & 1.60 \\
90 & 0.94 & 1.36 \\
\hline
\end{tabular}

The effect of the soaps of RSO on the thermal degradation of PVC was evaluated by comparing the values of $R_{t}$, the inhibition time obtained in the presence of the additive to $R_{t}{ }^{o}$, the corresponding value for the unstabilized PVC. For an additive to be considered an effective stabilizer for PVC, the value of $R_{t} / R_{t}{ }^{0}$ should be greater than 1 , the greater the divergence of the value from unity, the more effective the additive is considered in stabilizing PVC against thermal dehydrochlorination. The 
heat stabilizing effect of metal stearates or carboxylates in general, in PVC has been long explained in terms of the Frye-Horst mechanism in which the fatty acid salt of the metal (II) ion reacts with PVC by an esterifying displacement of chlorine; stabilization arising from substitution of labile chlorine atoms with more heat stable carboxylate groups. The results in Table 1 show that the order of stabilizing effectiveness is Ba-RSO > Cd-RSO.

Alkaline earth metal carboxylates reacts relatively slowly and results mainly in retardation of dehydrochlorination. The covalent metal carboxylates react rapidly and effectively inhibit dehydrochlorination. However, the covalent metal chloride produced by these reactions act as Lewis acid and accentuates dehydrochlorination. In order to enhance the heat stabilizing effectiveness of metal carboxylates, mixtures, usually (alkaline earth/covalent) metal carboxylates are used. Alkaline earth metal carboxylates undergo ester exchange reactions with covalent metal chlorides, thus regenerating the covalent metal carboxylate. Unlike the covalent metal chloride, alkaline earth chlorides do not promote dehydrochlorination. Thus, the alkaline earth carboxylates serve to regenerate the active stabilizer and remove the potentially destructive effect of the covalent metal chloride.

The synergistic effect of barium and cadmium stearates is generally interpreted as an exchange reaction between the barium salt acting as the donor reagent supplying the stabilizing anions that eventually end up on the polymer chain and cadmium chloride, which merely acts as the catalyst or intermediate transfer agent for the main reaction that displaces the labile chlorine on the polymer. However, when the content of $\mathrm{Cd}$ soap increased, there was a gradual reduction in the induction time.

Thermogravimetric analysis. The thermograms of unstabilized PVC and PVC stabilized with Ba and Cd soaps (single and admixtures) of RSO are shown in Fig. 5.

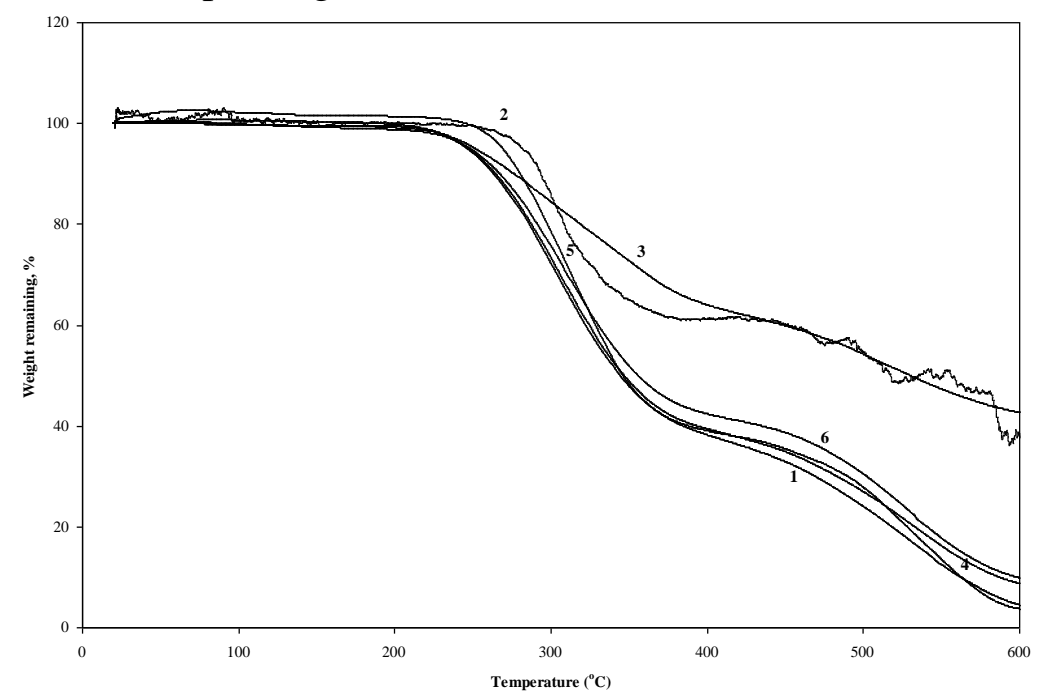

Fig. 5. TGA curves for PVC polymer stabilized with 1) No soap 2) Ba soap 3) Cd soap 4) $10 \% \mathrm{Cd}$ soap 5) $50 \% \mathrm{Cd}$ soap 6) $90 \% \mathrm{Cd}$ soap

The thermograms in Fig. 5 indicate that thermal degradation of PVC is a two step process: stage one, occurring approximately between 200 and $300^{\circ} \mathrm{C}$, at which $\mathrm{HCl}$ is considered the major volatile product of degradation and stage two; at higher temperatures at which low molecular weight hydrocarbons, such as benzene and toluene contribute to the measured weight loss. The behaviour of PVC during the stage one process is of more direct interest in stabilization studies [13].

The effect of the soaps of RSO on the thermal degradation of PVC was evaluated by comparing the values of incipient temperature of degradation, $T_{i}$, in the presence of the additives with the corresponding value in the absence of additive, $\mathrm{T}_{\mathrm{i}}{ }^{\mathrm{o}}$; the higher the value of $\mathrm{T}_{\mathrm{i}} / \mathrm{T}_{\mathrm{i}}{ }^{\mathrm{o}}$, the more effective the additive in stabilizing PVC against thermal degradation. 
The values of $\mathrm{T}_{\mathrm{i}} / \mathrm{T}_{\mathrm{i}}{ }^{\circ}$, residual weight of degraded $\mathrm{PVC}$ at $600^{\circ} \mathrm{C}$ and temperatures at which various extents of decomposition was attained as deduced from the thermograms are given in Table 2. The results in Table 2 appear consistent with the observed effectiveness of the additive in stabilizing PVC against thermal degradation from retardation index.

Table 2: Relative thermal stability of PVC stabilized with metal soaps of RSO

\begin{tabular}{|c|c|c|c|c|}
\hline \multirow[t]{2}{*}{ Additive } & \multirow[t]{2}{*}{$\begin{array}{l}\mathbf{T}_{\mathbf{i}} / \mathbf{T}_{\mathbf{i}}{ }^{0} \\
\left({ }^{0} \mathbf{C}\right)\end{array}$} & \multicolumn{2}{|c|}{$\begin{array}{l}\text { Temp. at which degradation } \\
\text { was attained }\left({ }^{\circ} \mathrm{C}\right)\end{array}$} & \multirow{2}{*}{$\begin{array}{l}\mathrm{Wt} \% \\
\text { remaining } \\
\text { at } 600^{\circ} \mathrm{C}\end{array}$} \\
\hline & & $10 \%$ & $30 \%$ & \\
\hline No soap & 0.00 & 262.0 & 303.6 & 4.5 \\
\hline Ba-RSO & 1.14 & 293.2 & 330.2 & 38.5 \\
\hline Cd-RSO & 0.96 & 276.3 & 361.1 & 42.7 \\
\hline \multicolumn{5}{|c|}{$\begin{array}{l}\text { Mixtures of } \mathrm{Ba} / \mathrm{Cd} \text { soaps of RSO: } \\
\text { (\% Cd-soap content) }\end{array}$} \\
\hline 10 & 1.00 & 264.0 & 305.6 & 8.8 \\
\hline 50 & 1.06 & 279.8 & 312.9 & 3.7 \\
\hline 90 & 1.02 & 267.0 & 310.3 & 9.9 \\
\hline
\end{tabular}

\section{Stabilization of Plasticized PVC with Ba and Cd soaps of RSO.}

Thermal dehydrochlorination studies. The effect of $\mathrm{Ba}$ and $\mathrm{Cd}$ soaps of $\mathrm{RSO}$ and their admixtures on the thermal dehydrochlorination of plasticized PVC was studied at $160^{\circ} \mathrm{C}$. Typical plots of the variation of conductivity with time using the PVC Thermomat equipment for P-PVC stabilized with binary mixtures of Ba and Cd soaps are shown in Fig. 6. Similar plots were obtained for the single soap mixtures and the dehydrochlorination characteristics from the curves are shown in Table 3.

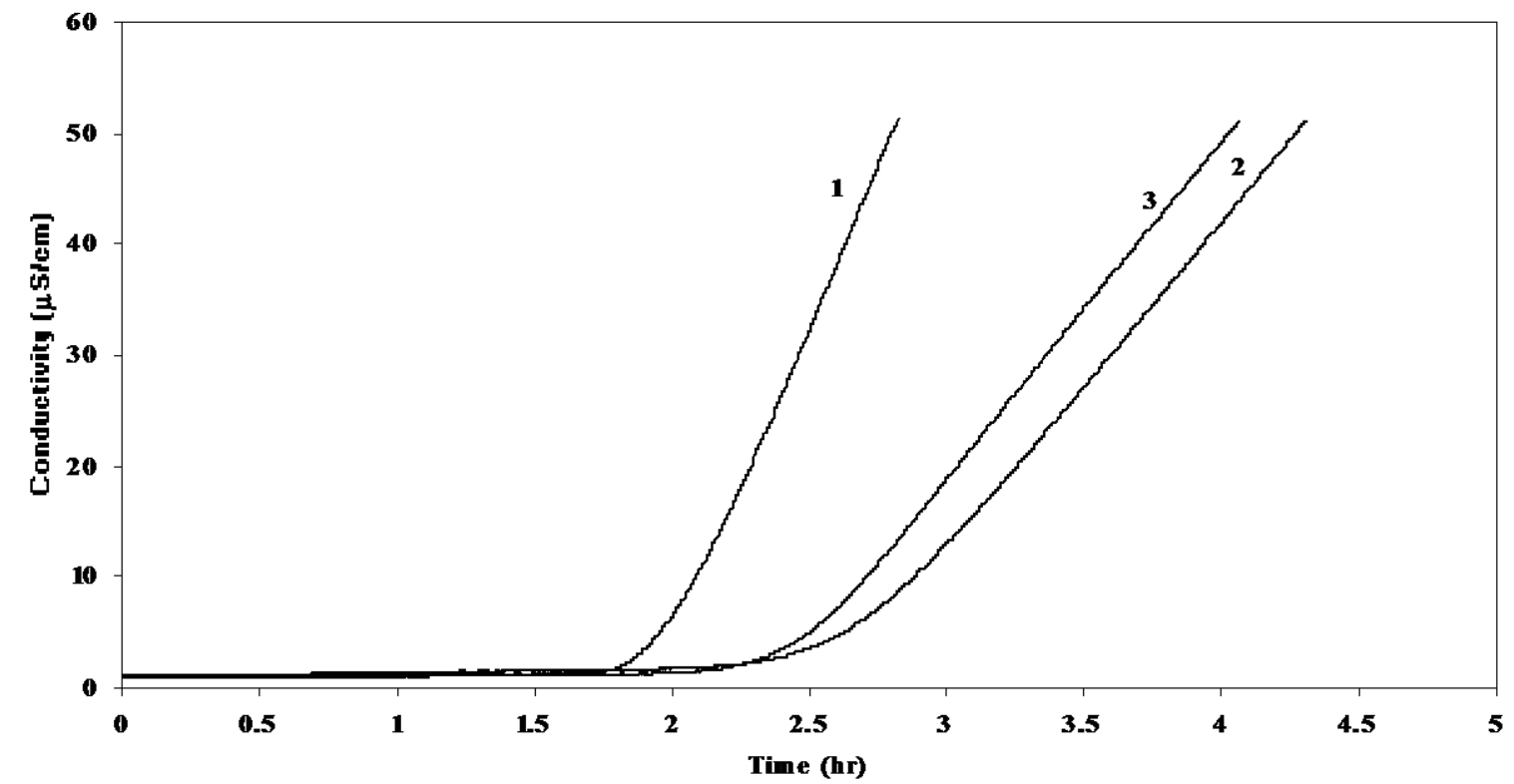

Fig. 6. Dehydrochlorination curves at $160^{\circ} \mathrm{C}$ for P-PVC stabilized with (1) $10 \%$ Cd soap (2) $50 \%$ Cd soap (3) $90 \%$ Cd soap. 
Table 3: Dehydrochlorination Characteristics obtained for P-PVC stabilized with metal soaps of RSO

\begin{tabular}{lcc}
\hline Additive & Induction time $(\mathbf{h})$ & Retardation index $\left(\mathbf{R}_{\mathbf{t}} / \mathbf{R}_{\mathbf{t}}^{\mathbf{0}}\right)$ \\
\hline None & 0.74 & 0.00 \\
Ba soap & 4.99 & 6.74 \\
Cd soap & 2.00 & 2.70 \\
Mixtures of Ba/Cd soaps of RSO: & \\
$(\boldsymbol{\%}$ Cd-soap content) & & \\
10 & 1.87 & 2.53 \\
50 & 2.64 & 3.57 \\
90 & 2.50 & 3.38 \\
\hline
\end{tabular}

The addition of the plasticizer, DOP, to PVC with metal soaps of RSO increased the induction times thereby decreasing the rate of dehydrochlorination. It has been shown that the use of plasticizers, for example, DOP with metal soaps such as $\mathrm{Cd}$, Ba and $\mathrm{Zn}$ increases the stability of PVC to both heat and light [14]. Synergistic effects are found to be higher and have more stabilizing effect on PVC when the metal soaps are blended in 50:50 weight ratios.

Thermogravimetric analysis. The thermograms obtained from the thermal treatment of plasticized PVC stabilized with barium and cadmium soaps of RSO using TGA are shown in Fig. 7 and the values of $\mathrm{T}_{\mathrm{i}} / \mathrm{T}_{\mathrm{i}}^{\mathrm{o}}$, residual weight of degraded PVC at $600^{\circ} \mathrm{C}$ and temperatures at which various extents of decomposition was attained are given in Table 4.

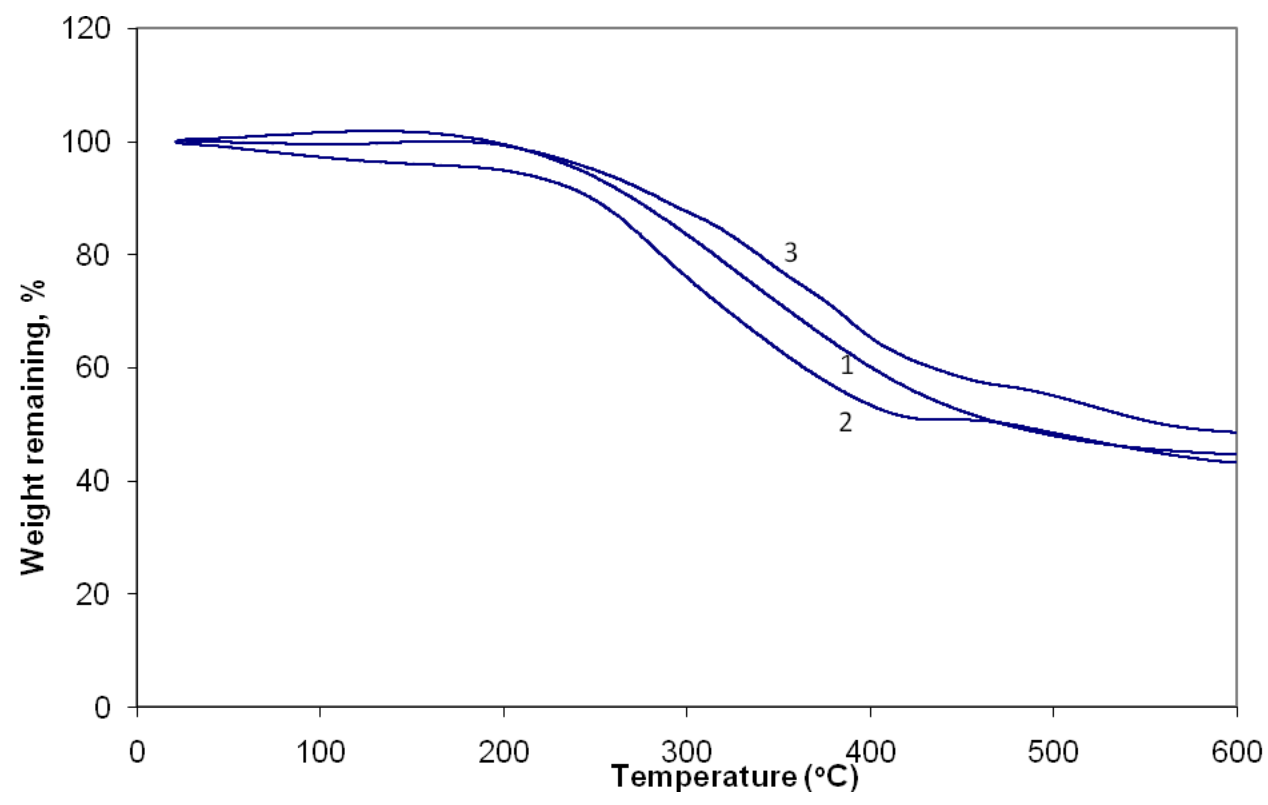

Fig. 7. TGA curves for plasticized PVC stabilized with 1) No soap 2) Ba soap 3) Cd soap 
Table 4: Relative thermal stability of plasticized PVC stabilized with metal soaps of RSO

\begin{tabular}{lcrcl}
\hline Additive & $\begin{array}{c}\mathbf{T}_{\mathbf{i}} / \mathbf{T}_{\mathbf{i}}^{\mathbf{0}} \\
\left({ }^{\mathbf{0}} \mathbf{C}\right)\end{array}$ & \multicolumn{2}{c}{$\begin{array}{c}\text { Temp. at which degradation } \\
\text { was attained }\left({ }^{\mathbf{0}} \mathbf{C}\right)\end{array}$} & $\begin{array}{l}\mathbf{W t \%} \\
\text { remaining }\end{array}$ \\
& & $\mathbf{1 0 \%}$ & $\mathbf{3 0 \%}$ & $\mathbf{6 0 0}^{\mathbf{0}} \mathbf{C}$ \\
\hline No soap & 0.00 & 247.7 & 320.7 & 43.2 \\
Ba-RSO & 1.00 & 270.1 & 355.7 & 44.6 \\
Cd-RSO & 1.01 & 284.4 & 381.7 & 48.6 \\
\hline
\end{tabular}

It has been shown that plasticizer addition to PVC resins change the degradation pattern of the resin [15]. However, the presence of barium and cadmium soaps of RSO improved the thermal stability of plasticized PVC. Previous studies on the use of metal soaps/epoxides of vegetable oils, notably soybean oil $[4,7,14,16]$ give evidence that these derivatives when added to rigid or plasticized PVC reduce the initial rate of dehydrochlorination and these corroborate with the findings in this study.

\section{Conclusion}

The effect of $\mathrm{Ba}$ and $\mathrm{Cd}$ soaps of RSO and their admixtures on the thermal stability of PVC in the powder and plasticized forms was evaluated using retardation indices from dehydrochlorination and incipient temperature of decomposition from thermogravimetry. In the presence of the soaps, the rate of retardation of $\mathrm{HCl}$ was improved compared to unstabilized PVC. The results obtained indicate that reliable data and information on the effectiveness of an additive as heat stabilizer for $\mathrm{PVC}$ in rigid and plasticized forms using these indices can be obtained. 


\section{References}

[1] O. Fenollar, D. Garcia, L. Sanchez, J. Lopez, R. Balart, Optimization of the curing conditions of PVC plastisols based on the use of an epoxidized fatty acid ester plasticizer, Eur. Polym. J. doi:10.1016/j.eurpolymj.2009.05.029 (2009) (in press).

[2] R. Kalouskova, M. Novotna, Z. Vymazal, Investigation of thermal stabilization of poly (vinyl chloride) by lead stearates and its combination with synthetic hydrotalcite, Polym. Degrad. Stab. 85(2004) $903-909$.

[3] E. Arkis, D. Balköse, Thermal stabilization of poly (vinyl chloride) by organotin compounds, Polym. Degrad. Stab. 88 (2005) 46 - 51.

[4] D. Balköse, H.I. Gokcel, S.E. Göktepe, Synergism of $\mathrm{Ca} / \mathrm{Zn}$ soaps in poly (vinyl chloride) thermal stability, Eur .Polym. J. 37 (2001) 1191 - 1197.

[5] S. Atakul, D. Balköse, S. Ulku, Synergistic effect of metal soaps and natural zeolite on poly (vinyl chloride) thermal stability, J. Vinyl Addit. Technol .11 (2005) 47 - 56.

[6] W. H. Starnes (Jr.), B. Du, S. Kim, V. G. Zaikov, X. Ge, E. K. Culyba, Thermal stabilization and plasticization of poly (vinyl chloride) by ester thiols: Update and current status, Thermochimica Acta, 442 (2006) 78 - 80.

[7] M.T. Benaniba, N. Belhaneche-Bensemra, G. Gelbard, Stabilization of PVC by epoxidized sunflower oil in the presence of zinc and calcium stearates, Polym. Degrad. Stab. 82 (2003) 245- 249.

[8] M. T. Taghizadeh, F. Fakhimi, Kinetic study of degradation and stabilizing effect of organic thermal stabilizers (EDTA, 1,2 propane diol, benzoic acid and phenol) for rigid poly (vinyl chloride), Iranian Polym. J.14 (2005) 685 - 692.

[9] G. Sivalingam, G. Madras, Effect of metal oxides/chlorides on the thermal degradation of poly (vinyl chloride), poly (bisphenol a carbonate) and their blends, Ind. Eng. Chem. Res. 43 (2004) $7716-7722$.

[10] N. A. Mohamed, M. W. Sabaa, A. A. Yassin, Organic thermal stabilizers for rigid poly (vinyl chloride) IV, N-aryl phthalimides, Polym. Degrad. Stab. 76 (2002) 355 - 365.

[11] T.O Egbuchunam, D. Balköse, F.E. Okieimen, Preparation and characterization of divalent metal soaps of rubber seed oil, J. Chem. Soc. Niger. 32(1) (2007) $61-68$.

[12] A. Broido, J. Polym. Sci. Part A2, 7 (1969) 1761 - 1773.

[13] F.E. Okieimen, O. C. Eromosele, Thermal stabilization of PVC with metal soaps of Khaya seed oil: Thermogravimetric studies, J. Appl. Polym. Sci. 77 (2000) 1432 - 1438.

[14] H. Baltacioglu, D. Balköse, Effect of zinc stearates and/or epoxidized soybean oil on gelation and thermal stability of PVC-DOP plastigels, J. Appl. Polym. Sci. 74 (1999) 2488 - 2498.

[15] A. Jimenez, V. Berenguer, J. Lopez, J. Vilaplana, New mathematical model on the thermal degradation of Industrial plastisols, J. Appl. Polym. Sci. 60 (1996) 2041 - 2048.

[16] R. Benavides, M. Edge, N.S. Allen, M. Shah, M.M. Tellez, The mode of action of metal stearate stabilizers in poly (vinyl chloride) III. Influence of pre-heating on polyene formation and secondary reactions, Polym. Degrad. Stab. 48 (1995) $377-385$. 